\title{
Research on the Teaching Reform of Translation Course for English Majors in the Context of Big Data
}

\author{
Wang Chen \\ Shaanxi Technical College of Finance and Economics, Shaanxi, China, 712000
}

Keywords: Big data; English major; Translation course

\begin{abstract}
The impact of big data in the field of higher education is increasingly apparent. In the era of big data, the teaching environment of translation course for English majors is characterized by rich teaching resources and online teaching methods. However, the big data also brings new challenges to the teaching of this course, such as over-reliance on the teaching resources of network education, confidentiality with traditional teaching methods, etc. Therefore, it is necessary to promote the teaching reform of this course by strengthening the rational utilization of teaching resources of network education and making comprehensive use of modern and traditional teaching methods.
\end{abstract}

Translation is an important part of English curriculum in Chinese universities. Translation, as an English teaching mode, is of great significance to uncontroversial English proficiency. Translation competence is an important criterion for assessing students' comprehensive English proficiency. In the 21st century, with the acceleration of the process of world integration, more and more trade is going to the world, and the market urgently needs professional English translators. Therefore, to improve the translation education level of English majors is of great practical significance to the individual development of students and the overall development of society.

\section{Current Situation of Translation Teaching For English Majors in China}

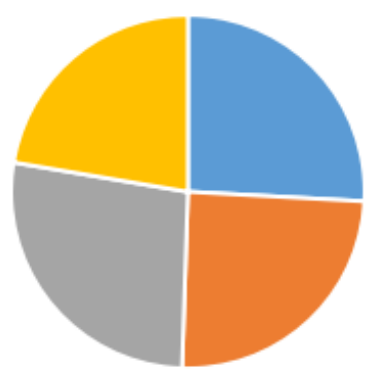

- Single Curriculum

- English textbooks can not keep up with the needs of the times

a Single Teaching Content

m unreasonable proportion of teaching methods and test evaluation contents

Figure 1.Current situation of translation teaching for English majors in China 
At present, many English educators still remain in the traditional stage of understanding English translation. They do not have a clear understanding of the difference between translation teaching and translation teaching methods. They do not have a unified understanding of the relationship between translation theory and practice in teaching. They do not have a clear definition of the proportion of translation in teaching and the focus of translation teaching, which makes English majors in China turn. There are many contradictions in translation teaching, which are embodied in the following aspects, as shown in figure1.

\subsection{Single Curriculum}

At present, there is a lack of translation courses in the curriculum of English majors in Chinese universities. The education of translation is mostly integrated into the explanation of English texts. College English teaching is characterized by more content and less class hours. Therefore, few students can really learn translation skills in their study. Most of them are mere translation teaching. Corresponding after-class exercises are too shallow to really strengthen translatable ability. In addition, some English majors in Colleges and universities will set up special translation courses, but most of them are arranged for the first semester or the second semester of their senior year, which is the busiest stage of interpersonal affairs. Most of them are busy with graduation and job hunting. It is difficult to ensure that students have enough time and energy to study professional translation courses, and the teaching effect is greatly reduced.

\subsection{English textbooks cannot keep up with the needs of the times}

Most of the translation textbooks used by English majors in Chinese universities were compiled in the last century or revised in this century. During this period, both Chinese-to-English and English-to-Chinese studies are in full swing, so the content of the textbook is very inconsistent with the international level of practical research, and a new set of translation textbooks is needed.

\subsection{Single Teaching Content}

With the continuous development of China's economy and the acceleration of the process of global integration, the worldwide demand for Chinese-English translation is gradually expanding. The traditional translation teaching in Chinese universities mostly translates English into Chinese to assess misunderstanding of English, which is seriously inconsistent with the current market demand and international situation.

\subsection{Unreasonable proportion of teaching methods and test evaluation contents}

Most English education practitioners do not pay enough attention to translation teaching in the process of English teaching. The emphasis of oral English, listening and translation is unreasonable, and there is not enough arrangement for evaluation and testing of translation, so it is impossible to effectively assess translatable level.

\section{The Impact of Big Data on the Teaching of Translation Course for English Majors}

As shown in figure 2, a detailed analysis is presented below. 
Enrichment of Teaching Resources

\section{Online Teaching Method}

Interaction of Teaching Evaluation

Figure 2.The Impact of Big Data on the Teaching of Translation Course for English Majors

\subsection{Enrichment of Teaching Resources}

Teaching resources refer to the sum of information, technology and environment provided to ensure the orderly and effective development of teaching activities, such as teachers, textbooks, classrooms, training bases and educational policies. Before the big data era, the teaching resources of translation courses for English majors were mainly traditional teaching resources such as teachers, textbooks and classrooms, and these resources were very limited. In the era of big data, all kinds of platform resources, information resources and other teaching resources are not only complete, but also extremely rich in content. Such as Blackboard Network Teaching Application Management Platform, Course Museum, Micro blog, Network Forum and other platform resources; such as e-books, courseware, exercise library, network audio and video information resources.

These teaching resources are interactive and timeliness, which not only brings diversified choices for teachers to organize teaching, but also stimulates studentships, enhances their interest in learning and learning effect, and changes the traditional teaching and information dissemination mode. In the era of big data, English is the first official language in the world, so its teaching resources become more rich and diversified.

\subsection{Online Teaching Method}

Online teaching refers to the use of computer technology and Internet technology to transfer knowledge, so that students and teachers can break through the time and space constraints and start teaching activities. Because of its flexible form and low cost, online teaching has developed rapidly in recent years. Some studies have shown that the main mode of continuing education in Korea is online teaching, $78 \%$ of its universities have established online teaching platform for learners to use; and other studies predict that by 2018, the number of students using the Internet for learning in the United States will exceed the number of face-to-face teaching.

Taking the combination of large-scale open online courses and translation courses for English majors as an example, by introducing the platform of English translate courses, the course participation, feedback, homework, discussion, evaluation and examination are all presented on the platform. Students can use the mode of "online learning" and "classroom face-to-face teaching" to conduct mixed learning, which can improve their learning comprehensively. Interest, participation and sense of cooperation in translation course can really improve the teaching quality and efficiency. At the same time, micro-courses and micro-courses closely linked with MOU courses can also better realize the online teaching mode of translation course for English majors.

\subsection{Interaction of Teaching Evaluation}

Teaching evaluation is an activity and process of systematically recognizing, evaluating and judging the value of classroom teaching-related activities by scientifically setting up teaching 
evaluation indexes and evaluation items in accordance with teaching characteristics and laws. In traditional teaching, mistranslated can only be corrected by teachers, and most of the evaluations are given by teachers in writing. In this one-way mode, teachers provide little information and students have limited reference value. At the same time, students are still unable to understand some knowledge points because they cannot communicate and interact with teachers directly. The application of big data has changed this one-way evaluation model, and the assessment of translatable tasks in and out of class is no longer limited to teachers' written form.

Teachers can organize on-line discussions with students through the school's teaching platform, and have extensive and in-depth exchanges with students. They can also communicate and interact between teachers and students through "after-school forum" or new media such as micro-mail and micro-blog. Therefore, in the era of big data, the teaching evaluation of translation course for English majors can fully realize all-round interaction.

\section{Strategies for the Teaching Reform of Translation Course for English Majors in the Big Data Era}

\subsection{Reasonable utilization of teaching resources in online education}

Reasonable Utilization of Teaching Resources of Network Education the era of big data, the increasingly abundant teaching resources of network education is the necessity of social development. How to make rational and effective use of teaching resources of network education is a problem that all participants in higher education must face. From the school's point of view, colleges and universities should attach great importance to the effective use of teaching resources of network education according to the development trend of the times, and design a teaching resources management platform of network education based on the needs of teachers and students of the school, so as to store excellent educational and teaching resources inside and outside the school as far as possible on the school platform for the use of teachers and students of the whole school.

From the teacher's point of view, the teachers of translation courses for English majors should integrate their understanding of translation and their accumulated experience into teaching in the preparation and teaching of courses. From the student's point of view, when completing homework, we need to think deeply at first. We can't use the teaching resources of network education directly to complete homework. Only in this way can we really improve translation skills and form our own translation style. In a word, teachers and students should not rely too much on teaching resources of online education.

\subsection{Comprehensive use of modern and traditional teaching methods}

Teachers are organizers, guiders and collaborators of classroom teaching. In the era of big data, for the teaching of translation courses for English majors, teachers should play multiple roles of organizers, guiders and collaborators. Flexible use of modern teaching methods and traditional teaching methods is essential. Firstly, teachers should recognize the value and advantages of traditional teaching methods. For some important translation theories and usages, they should mainly use traditional teaching methods such as blackboard writing, question-asking, group discussion and so on to inspire studentship. For some individual unique insights, teachers should also try to use traditional teaching methods. Secondly, for some translation practices involving cultural and political content, teachers should make full use of modern teaching methods to show some translated works to students in full, and deepen their understanding. In a word, teachers of translation courses for English majors should not blindly pursue modern teaching methods. They should make full use of various teaching methods to eliminate studentship conflicting feelings. 


\subsection{Strengthen the Identification of Teaching Resources in Online Education}

In the era of big data, although the teaching resources of network education are rich and varied, they are also in harmony with each other and need to be identified before they can be applied. For teachers, they should search the relevant teaching resources of online education closely and use them as supplementary materials to enrich and expand the teaching content after careful self-examination. Especially for courseware, classroom exercises, examination questions and so on, teachers should add the identified network education teaching resources into the relevant content of their own design according to the requirements of the syllabus. For students, they should treat translation learning resources on the Internet with dialectical thinking. They should not only identify their advantages and disadvantages, but also make rational use of them.

\section{Conclusion}

Especially for the teacher's well-designed exercise materials, students should use their knowledge to translate carefully first, then use the relevant software or other people's results to compare, find their own shortcomings and improve them. Only by improving head teacher students' identification consciousness and ability can we really improve the teaching and learning effect.

\section{References}

[1] Gong Shimming. On Questioning Strategies in English Classroom [J]. Journal of Jungian Institute of Education Society Science Edition, 1999, (l)

[2] Gong Shimming. Questionnaires and Classroom Interaction in English Classroom Teaching (IJ). Jungian Technology Journal of Technical Teachers College, 2006, (2)

[3] Jingo Abeyance. Unquestioning and classroom communication fields]. Reckoning Normal University, 2002.

[4] H Chunky. English Teaching Method. College Entrance Examination Education Press, 1999.

[5] Henge Picayune. Classroom Questioning and Anxiety Control [J]. Foreign Language, 2003, (3):26 13 